\title{
Labor Companionship in Labor and Delivery at Debremarkos Town Public Health Facilities: Magnitude and Associated Factors
}

\author{
Melaku Hunie Asratie' \\ Hussien Mohammed Assfaw ${ }^{2}$ \\ Mulunesh Abuhay' \\ 'Department of Women's and Family \\ Health, School of Midwifery, College of \\ Medicine and Health Sciences, University \\ of Gondar, Gondar, Ethiopia; \\ ${ }^{2}$ Department of Clinical Midwifery, \\ School of Midwifery, College of Medicine \\ and Health Sciences, University of \\ Gondar, Gondar, Ethiopia
}

Background: Labor companionship is a human interactive process that provides social support during the childbirth process. Despite it being one component of respectful maternity care (RMC) that is used for quality assurance to achieve the sustainable goal of maternal and neonatal mortality reduction, there is limited evidence about the current status of birth companionship. The study was aimed to assess labor companion and its associated factors at Debremarkos town public health facilities.

Methods: An institution-based cross-sectional study design was conducted. The study was conducted at Debremarkos town from February 1/2021 to March 30/2021. From the 559 sample size, 548 women participated in the study. A systematic random sampling technique was used. A pre-tested interviewer-administered questioner was used, data were entered and analyzed with Epi-data version 4.60 and SPSS version 25.0. Bivariable regression was done and variables with $\mathrm{p}$-value $<=0.20$ were analyzed with multivariable logistic regression. Variables with $p$-value $</=0.05$ were considered significantly associated with labor companionship. Hosmer-Lemeshow goodness of fit was checked and all multi-collinearity of variables with variance inflation factors (VIF) up to 10 was tolerated.

Results: A total of 548 participants were involved in the study with a $98.03 \%$ response rate. The magnitude of labor companionship was found to be $14.6 \%$ (11.7-17.5). Women who had complicated pregnancy (adjusted odds ratio $[\mathrm{AOR}]=5.53$; 95\% CI: 3.09-9.92), women's desire for a labor companion $(\mathrm{AOR}=3.63 ; 95 \% \mathrm{CI}: 1.51-8.69)$, being primipara $(\mathrm{AOR}=3.49 ; 95 \% \mathrm{CI}$ : 1.93-6.35), labor followed by female skilled birth attendant ( $\mathrm{AOR}=0.37 ; 95 \% \mathrm{CI}: 0.17-0.82$ ), and women's perceived busyness of skilled birth attendant ( $\mathrm{AOR}=0.13 ; 95 \% \mathrm{CI}: 0.07-0.23$ ) were significantly associated with labor companionship.

Conclusions: Labor companionship was found to be low. Giving emphasis on the desire, primipara, complicated pregnancy, sex of skilled birth attendant and women perceived busy skilled birth attendant were suggested for the improvement of labor companionship.

Keywords: labor companionship, Debremarkos town, Ethiopia

\section{Background}

For many women being pregnant is not just a matter of having a baby, it is a matter of life and death. ${ }^{1}$ Across time and cultures, women have been supported during labor by other women who are experienced in providing continuous emotional and physical support. However, this component of maternal care is largely missed when childbirth takes place in health facilities because of intrapartum care focus on utilization of technological aspect of care like CTG for feto-maternal monitoring rather than supportive aspect maternal care during the end of the 20th century. ${ }^{2}$ 
Labor companionship is a human interactive process that provides tangible continuous social support or assistance (emotional, cognitive, and physical support) during the childbirth process to help women cope with the stress of labor with an empathic person. Companion is any person chosen by a woman for providing continuous support like advice, information, and comfort during labor and childbirth. ${ }^{2-4}$

Evidence suggested that labor and childbirth with companionship have both long- and short-term obstetrical and postpartum benefits, such as the reduction of anxiety, 5,6 postpartum depression, ${ }^{6}$ emergency cesarean section rate, ${ }^{3,6,7}$ episiotomy, fetal distress, instrumental delivery, need for pain medication, ${ }^{3,6}$ pain perception, ${ }^{5}$ length of labor, ${ }^{3,6-8}$ need of oxytocin for augmentation, ${ }^{6}$ and meconium-stained amniotic fluid. ${ }^{9}$ Companionship is said to increase spontaneous vaginal birth, positive feelings about the childbirth experience, ${ }^{6}$ exclusive breastfeeding practices, ${ }^{3,6}$ rate of breast feeding initiation, ${ }^{6}$ maternal satisfaction, ${ }^{9,10}$ five-minute APGAR score, ${ }^{3,8,11}$ motherbaby bonding, ${ }^{6}$ skin-to-skin contact, easier and enjoyable labor, and sufficient milk for baby. ${ }^{12}$

Additionally, evidence also revealed that utilization of a labor companion reduced the risk of sub-standard care by 10 times, ${ }^{13}$ reduction of childbirth fear by $0.866,{ }^{14}$ reduction of mistreatment, such as stigma, non-consented vaginal examination, poor communication, and longer wait times ${ }^{15}$ compared to no labor companion being present. Furthermore, laboring women's self-efficacy increased by 0.903 due to the presence of a preferred birth support companion in addition to routine childbirth care given by SBAs. ${ }^{14}$ In conclusion the absence of a labor companion is a predominant factor in a negative birth experience. ${ }^{16}$

The practice of labor companionship is also necessary for family members and health care providers. Continuous support of a woman from her husband increases the satisfaction of the husband and father-baby bonding. ${ }^{17}$

However, despite scholars clearly stating the benefits and women's willingness, desire, and/or profound need for companionship during labor, ${ }^{18}$ many health care facilities in developing countries still do not promote the practice of companionship during labor and delivery. ${ }^{19-21}$ Because of this many women in LMICS choose home and TBA than health facilities and SBA respectively to give childbirth, ${ }^{22,23}$ more than half of women in Ethiopia still deliver at home. ${ }^{24}$

As a result, maternal and neonatal mortality is still a tragic event around the globe, especially in developing countries. Maternal mortality ratio is significantly different between developed and developing worlds (11/100,000 and $462 / 100,000$, respectively). ${ }^{25}$ This discrepancy is due to lack of quality of care and the low utilization of institutionalized, client-centered and continuous preferred companion-supported care, especially in less developed countries, including Ethiopia. ${ }^{26-28}$

To overcome these problems different countries, such as South Africa, implement doula care ${ }^{29}$ and different scholars-WHO, FIGO, Ethiopian midwife association, among others - strongly recommend practicing labor companionship as the norm rather than the exception. ${ }^{3,4,30-32}$ The Federal Ministry of Health of Ethiopia has also endorsed/accepted these principles and adopted them, and streamlined/included in the package in keeping with the launching of the Respectful Maternity Care (RMC).

Even though the principle of birth companion utilization is endorsed, adopted, and included in the Ethiopian Ministry of Health's RMC package, there is insufficient data about the extent of implementation of labor companionship in our country's health institutions, despite extensive Internet-based research. Therefore this study aims to assess the prevalence of labor companion utilization and its associated factors among postnatal mothers in the public health institutions of Debremarkos town.

Knew a time focusing on the quality of service is a concern globe especially developing countries government agenda including Ethiopia to achieve sustainable development goal by 2030. To achieve this goal and improve quality care client center care like utilization of companion of choice is a hearty intervention.

Identifying the labor companion utilization gap will play an important role for stack holders who work to provide a positive childbirth experience by developing and incorporating a labor companion strategy, especially in a diverse cultural heritage, low institutional delivery coverage, and high maternal and neonatal mortality countries like Ethiopia. Therefore, this study can provide a clue that can be used to improve practice and policies on birth companionship in our country's health institutions by advocating companionship as the norm, rather than complementary clinical service provision, in order to reach the goal of sustainable development and Ethiopian ministry of a health plan.

Even though companionship plays a significant role in the reduction of maternal and neonatal mortality and morbidity, evidence related to the utilization of a labor companion is limited and the practice was also uncommon during my exposure to practice as a clinician in the midwifery profession in our public hospitals. Therefore this 
study explores all aspects of labor companionship in our setup and offers recommendations for future practice, especially in the study area.

Furthermore, this research will objectively identify the silent challenges of companionship utilization and will give some clue of solutions to tackle it according to other countries' experiences. Additionally, this study finding also provides important information for future researchers who are interested in this specific area.

\section{Methods}

\section{Study Design Area and Period}

An institution-based cross-sectional study design was conducted from 1 February 2021 to 30 March 2021. This study was conducted at Debremarkos town public health institutions, EastGojam Ethiopia. Debremarkos town is an administrative town of the east Gojjam zone, which is located 276 kilometers from Bahr Dar (capital city of Amhara region) and 300 kilometers from Addis Ababa (the capital city of Ethiopia). It has a latitude and longitude of $10^{\circ} 20^{\prime} \mathrm{N} 37^{\circ} 43^{\prime} \mathrm{E}$ and an elevation of 2446 meters. According to the population projection for Ethiopia for all regions at woreda level from 2014-2017, the total population of the town is estimated to be 92,470 . Among these 46,738 are females. Currently it has seven kebeles (the smallest administrative unit in Ethiopia). This town has 1 referral hospital and 3 public health centers. All public health facilities of the town provide maternity care services, including intrapartum care.

\section{Inclusion Criteria}

All postpartum mothers who gave labor in Debremarkos town public health institutions during data collection period.

\section{Exclusion Criteria}

Women who were seriously ill or unable to interviewed due to physical or mental problems during data collection period.

All mothers who gave birth with elective cesarean section during the data collection period.

All postnatal mothers who were admitted to the facility after second stage.

\section{Sample Size Determinations}

The sample size of the study was 559, which was determined with the consideration of proportion of companionship utilization of $13.8 \%$ from a previous study carried out in Arbaminch, Ethiopia, ${ }^{41}$ 95\% confidence level, 3\% margin of error, $10 \%$ non-response rate. Then: $\mathrm{n}=(Z \alpha / 2)^{2} \times$ $p(1-p) / d^{2}$ where: $\mathrm{n}=$ sample size, $\mathrm{p}(0.138)=$ proportion of women utilize labor companion during labor. Then $\mathrm{n}=508$ by adding $10 \%$ non-response rate, $\mathrm{n}=559$

\section{Sampling Technique}

This study was conducted at all public health institutions of Debremarkos town with proportional sample size allocation based on the number delivery reports from each health facility two months prior to the study period. Calculated $\mathrm{k}$-factors for each selected facility was 2 according to their delivery registration book as a sampling frame (ie $\mathrm{k}=\mathrm{N} / \mathrm{n} ; \mathrm{N}$ as total study population in each health institutions, $\mathrm{n}$ as allocated sample size of each health facilities). After eligibility criterion was checked using a record review, the study unit was selected by a systematic random sampling technique with delivery time as a frame of reference. The starting point of each interview was obtained using a lottery method and the interview was carried out in every other client interval for each facility until fulfillment of allocated sample size. A selected client who did not volunteer to participate in the study was considered a 'non-response.'

\section{Operational Definition Labor Companionship/Utilization of Labor Companion}

A women having a continuous emotional, tangible, informational, and social support with a preferred companion from their social network during labor on the ward. ${ }^{4}$

\section{Data Collection Tools and Procedure}

Data were collected with a pre-tested semi-structured interviewer-administered questionnaire with trained data collectors. Problems faced during data collection were solved at the point of data collection. On top of that there were continuous follow ups and supervision by a supervisor and principal investigator throughout the data collection period. The questionnaire was taken from a review of all available relevant literature and adapted to suit the study context. Questionnaires were grouped and arranged according to the particular objective that they should address.

\section{Data Quality Controls}

To assure data quality properly designed data collection tools were developed and a pre-test was conducted with 
$5 \%{ }^{28}$ of the participants of this sample at Lumama Primary Hospital one week prior to the actual data collection in order to check the validity and reliability of the questionnaire with regard to the objective of the study. One day intensive training on the data collection tool, ethical conduct including COVID-19 prevention and quality of data collection was provided for data collectors and supervisors. The questionnaire was translated to Amharic to make it understandable by the study participants and then was retranslated to English by another person to check whether the translation was consistent. The data collectors were strictly followed by the supervisors and reported to the principal investigator on a daily basis. The supervisors and principal investigator supervised the correct implementation of the procedure and checked the completeness and logical consistency during data collection.

\section{Data Processing and Analysis}

All completed questionnaire were checked for completeness and internal consistency by the principal investigator and the coordinators each day and a code was given to the completed questionnaires. Data were cleaned before and after entry. Across checking data were coded and entered with epi-data version 4.6 and analysis with statistical package for the social sciences (SPSS) version 23 after coding and recoding. Data cleaning was performed to check for accuracy, consistencies, and values. Then any form of errors were identified and corrected. Descriptive statistics like text, frequency distribution, percentage, tableswere used to describe and summarize the study population in relation to relevant variables. Both bivariable and multivariable logistic regression models were used to identify factors associated with the outcome variable. All variables with a p-value less than 0.20 with bi-variable analysis were entered in to multivariable analysis that was used to not overlook associated factors. Then a multiple logistic regression analysis was performed to investigate independent predictors by controlling for possible confounders. Finally, variables whose $p$ value was $<0.05$ in logistic regression were considered as the cutoff point for statistically significance association. The HosmerLemeshow test was used to check goodness of fit of the models. Multicollinearity was diagnosed using variance inflation factor (VIF) and all covariates having a value VIF up to 10 were tolerated.

\section{Results}

\section{Socio-Demographic Characteristics of Study Participant}

From the initially planned sample size of 559 individuals, data was collected from 548 participants with a response rate of $98.03 \%$. The median age of respondents was 27 years (with IQR: $24-30$ years) and more than half (52.7\%) of women were within the age category of 25-34 years. Most (96.9\%) respondents were Orthodox Christian by religion and two-thirds $(66.8 \%)$ of the study participants live in rural areas. Three in $10(29.9 \%)$ respondents were housewives by occupation. About 153 (27.9\%) study participants did not attain a formal education. More than half (56.4\%) of the respondents' average monthly income was greater than or equal to 3000 ETB. The majority (99.1\%) of study participants were from the Amhara ethnic group. About $96.2 \%$ of the participants were married and nearly one-third (32.6\% and 31.3\%) of their husbands' education and occupation was college and above and farming, respectively (Table 1).

\section{Maternal Obstetric Characteristics Respondents}

From the total study participants, 333 (60.8\%) and 306 (55.8\%) mothers were multigravida and multipara respectively. Among multigravida women, 88 (26.4\%) and 64 $(19.2 \%)$ had history of at least one abortion and bad obstetric history (BOH) respectively. Nearly one fifth $(18.8 \%)$ of interviewed women had at least one pregnancy complication. From all interviewed mothers the majority (98.7\%) had no history of chronic illness and $61.9 \%$ had not faced any labor-delivery complications. About $27.6 \%$ of the study participants had a complicated pregnancy. Three-quarters $(74.6 \%)$ of the study participants were delivered after spontaneous vaginal delivery (Table 2).

\section{Maternal Health Service Related Variables}

The majority (96\%) of mothers had at least one ANC visit and $73.4 \%$ of them were informed about at least a single component of birth preparedness and complication readiness during pregnancy. Nearly one-fifth (18.4\%) of the study participants were informed about birth companion selection during their ANC follow-up time. Among 526 participants who had ANC follow up, 73.4\% of them had four or more visits. For this labor and delivery, one tenth $(10.4 \%)$ of study participants were delivered at health center (Table 3). 
Table I Sociodemographic Characteristics of Respondents at Debre Markos Town, NorthWest Ethiopia from February to March 2021

\begin{tabular}{|c|c|c|c|c|}
\hline S.No & Variables & Categories & Frequency & Percentage \\
\hline \multirow[t]{3}{*}{ I } & Age $(n=548)$ & 15 to 24 & 156 & $28.5 \%$ \\
\hline & & 25 t0 34 & 289 & $52.7 \%$ \\
\hline & & 35 to 49 & 103 & $18.8 \%$ \\
\hline \multirow[t]{2}{*}{2} & Residence $(n=548)$ & Rural & 366 & $66.8 \%$ \\
\hline & & Urban & 182 & $33.2 \%$ \\
\hline \multirow[t]{3}{*}{3} & Religion $(n=548)$ & Orthodox & 531 & $96.9 \%$ \\
\hline & & Muslim & 16 & $2.9 \%$ \\
\hline & & Protestant & $\mathrm{I}$ & $0.2 \%$ \\
\hline \multirow[t]{3}{*}{4} & Ethnicity $(n=548)$ & Amhara & 543 & $99.1 \%$ \\
\hline & & Agew & 4 & $0.7 \%$ \\
\hline & & Oromo & 1 & $0.2 \%$ \\
\hline \multirow[t]{4}{*}{5} & Educational status $(n=548)$ & No formal education & 153 & $27.9 \%$ \\
\hline & & Primary education & 149 & $27.2 \%$ \\
\hline & & Secondary education & 102 & $18.6 \%$ \\
\hline & & College and above & 144 & $26.3 \%$ \\
\hline \multirow[t]{6}{*}{6} & Occupation $(n=548)$ & House wife & 164 & $29.9 \%$ \\
\hline & & Government employee & 106 & $19.3 \%$ \\
\hline & & Private worker & 48 & $8.8 \%$ \\
\hline & & Merchant & 64 & $11.7 \%$ \\
\hline & & Farmer & 144 & $26.3 \%$ \\
\hline & & Others $^{\mathrm{a}}$ & 22 & $4 \%$ \\
\hline \multirow[t]{2}{*}{7} & Marital status $(\mathrm{n}=\mathbf{5 4 8})$ & Married & 497 & $90.7 \%$ \\
\hline & & Single(unmarried)/ Divorced /Separated & 51 & $9.3 \%$ \\
\hline \multirow[t]{2}{*}{8} & Average monthly income $(n=548)$ & Less than 3000 & 239 & 43.6 \\
\hline & & $\geq 3000$ & 309 & 56.4 \\
\hline \multirow[t]{4}{*}{9} & Husband's education $(\mathbf{n = 5 2 7})$ & No formal education & 117 & $22.2 \%$ \\
\hline & & Primary school & 122 & $23.1 \%$ \\
\hline & & Secondary school & 116 & $22 \%$ \\
\hline & & College and above & 172 & $32.6 \%$ \\
\hline \multirow[t]{6}{*}{10} & Husband's occupation $(n=527)$ & Farmer & 165 & $31.3 \%$ \\
\hline & & Government employee & 132 & $25 \%$ \\
\hline & & Merchant & 111 & $21.1 \%$ \\
\hline & & Private worker & 87 & $16.5 \%$ \\
\hline & & Daily laborer & 21 & $4 \%$ \\
\hline & & Others ${ }^{b}$ & 11 & $2.1 \%$ \\
\hline
\end{tabular}

Notes: ${ }^{a}$ Other includes: student, NGO, jobless and daily laborer. ${ }^{\mathrm{b}}$ Other include: jobless, NGO, intermid.

\section{Labor Companion Utilization}

For all participants the magnitude of labor companionship was found to be $14.6 \%$ (11.7-17.5\%) (Figure 1). From those who utilized a labor companion 4 out of 10 were by their husbands (39.4\%), followed by mother/mother-in-law (35.5\%). Participants who were accompanied from home to the health facility (547), more than two-thirds were accompanied by their husbands (78.4\%), followed by mother/mother-in-law (37.5\%), sister/sister-in-law (35.6\%), father/father-in-law (17.2\%), brother (16.1\%) and friends/ neighbors (16.1\%). Among respondents (547) who had a companion from their social networks, $55.21 \%$ of them were not allowed their companion of choice, whereas 10 $(1.8 \%, 12.8 \%$, and $30.16 \%)$ of them were allowed to have 
Table 2 Maternal Obstetric Characteristics of Study Participant at Debremarkos Town, Northwest Ethiopia from February to March 2021

\begin{tabular}{|c|c|c|c|c|}
\hline S.No & Variables & Categories & Frequency & Percent (\%) \\
\hline \multirow[t]{2}{*}{ I } & \multirow[t]{2}{*}{ Gravidity $(n=548)$} & Primigravida & 215 & $39.2 \%$ \\
\hline & & Multigravida & 333 & $60.8 \%$ \\
\hline \multirow[t]{2}{*}{2} & \multirow[t]{2}{*}{ Parity $(n=548)$} & Primipara & 242 & $44.2 \%$ \\
\hline & & Multipara & 306 & $55.8 \%$ \\
\hline \multirow[t]{6}{*}{3} & \multirow[t]{6}{*}{ Pregnancy status $(\mathbf{n}=\mathbf{5 4 8})$} & Planned & 507 & $92.5 \%$ \\
\hline & & Un-planned & $4 I$ & $7.5 \%$ \\
\hline & & Wanted & 534 & $97.4 \%$ \\
\hline & & Un-wanted & 14 & $2.6 \%$ \\
\hline & & Supported & 528 & $96.4 \%$ \\
\hline & & Un-supported & 20 & $3.6 \%$ \\
\hline \multirow[t]{2}{*}{4} & \multirow[t]{2}{*}{ Complicated pregnancy $(n=548)$} & Yes & 151 & $27.6 \%$ \\
\hline & & No & 397 & $72.4 \%$ \\
\hline \multirow[t]{2}{*}{5} & \multirow[t]{2}{*}{$\mathrm{BOH}(n=333)$} & Yes & 64 & $19.2 \%$ \\
\hline & & No & 269 & $80.8 \%$ \\
\hline \multirow[t]{2}{*}{6} & \multirow[t]{2}{*}{ History of abortion $(\mathbf{n}=\mathbf{3 3 3})$} & Yes & 88 & $26.4 \%$ \\
\hline & & No & 245 & $73.6 \%$ \\
\hline \multirow[t]{2}{*}{7} & \multirow[t]{2}{*}{ Pregnancy complication $(\mathbf{n = 5 4 8})$} & Yes & 103 & $18.8 \%$ \\
\hline & & No & 445 & $81.2 \%$ \\
\hline \multirow[t]{2}{*}{8} & \multirow[t]{2}{*}{ History of chronic illness $(n=548)$} & Yes & 7 & $1.3 \%$ \\
\hline & & No & 541 & $98.7 \%$ \\
\hline \multirow[t]{2}{*}{9} & \multirow[t]{2}{*}{ Labor-delivery complication $(\mathbf{n}=\mathbf{5 4 8})$} & Yes & 209 & $38.1 \%$ \\
\hline & & No & 339 & $61.9 \%$ \\
\hline \multirow[t]{3}{*}{10} & \multirow[t]{3}{*}{ Current mode of delivery $(n=548)$} & SVD & 398 & $72.6 \%$ \\
\hline & & Cesarean delivery & 111 & $20.3 \%$ \\
\hline & & Instrumental/episiotomy assisted & 39 & $7.1 \%$ \\
\hline
\end{tabular}

Abbreviation: $\mathrm{BOH}$, bad obstetric history.

support all of the time, most of the time, and a few times, respectively, during their labor process after admission to the labor ward. Among respondents who were allowed to have a labor companion on the labor ward, $98.8 \%$ of them were accompanied by their preferred companion.

\section{Factors Associated with Labor Companion Utilization}

Bi-variable and multivariable binary logistic regression analyses were done to identify factors associated with labor companion utilization. On bi-variable binary logistic regression mothers' age, parity, complicated pregnancy, current mode of delivery type, busyness of staff, sex of SBAs mostly followed, women's future desire, knowledge of women, marital status, and number of pregnancies had an association with utilization of labor companion. However, after controlling confounding on multivariable logistic regression analysis for complicated pregnancies, SBAs busyness, sex of SBAs mostly followed, parity and future desire were significantly associated with labor companion utilization.

Those women who had complicated pregnancy were 5.53 times more likely utilize a labor companion compared to their counterparts (adjusted odds ratio $[\mathrm{AOR}]=5.53$, 95\% CI: 3.09-9.92). Women who had a future desire for labor companion utilization were $3.63(\mathrm{AOR}=3.63,95 \%$ CI: $1.51-8.69)$ times more likely to utilize a labor companion compared to those women who had no future desire.

Being Primipara were 3.49 times more likely utilize labor companion compared to multipara women (AOR=3.49, 95\% CI: 1.93-6.35). According to the women's perspective, the busier the staff were decreased the odds of labor companion utilization with $87 \%$ 
Table 3 Maternal Health Service Related Variables of Study Participant at Debremarkos Town, North West Ethiopia from February to March 2021

\begin{tabular}{|c|c|c|c|c|}
\hline S.No & Variables & Categories & Frequency & Percent (\%) \\
\hline I & At least one ANC $(n=548)$ & $\begin{array}{l}\text { Yes } \\
\text { No }\end{array}$ & $\begin{array}{l}526 \\
22\end{array}$ & $\begin{array}{l}96 \% \\
4 \%\end{array}$ \\
\hline 2 & Number of ANC $(n=526)$ & $\begin{array}{l}\text { Less than } 4 \\
\geq \text { four }\end{array}$ & $\begin{array}{l}140 \\
386\end{array}$ & $\begin{array}{l}26.6 \% \\
73.4\end{array}$ \\
\hline 3 & Counseled on BP and CR during ANC $(n=526)$ & $\begin{array}{l}\text { Yes } \\
\text { No }\end{array}$ & $\begin{array}{l}387 \\
139\end{array}$ & $\begin{array}{l}73.6 \% \\
26.4 \%\end{array}$ \\
\hline 4 & Informed about birth companion selection at ANC $(\mathbf{n}=\mathbf{3 8 7})$ & $\begin{array}{l}\text { Yes } \\
\text { No }\end{array}$ & $\begin{array}{l}110 \\
277\end{array}$ & $\begin{array}{l}28.4 \% \\
71.6 \%\end{array}$ \\
\hline 5 & Current labor delivery place $(n=548)$ & $\begin{array}{l}\text { Hospital } \\
\text { Health center }\end{array}$ & $\begin{array}{l}491 \\
57\end{array}$ & $\begin{array}{l}89.6 \% \\
10.4 \%\end{array}$ \\
\hline 6 & Previous delivery place $(n=306)$ & $\begin{array}{l}\text { Health facility } \\
\text { Home } \\
\text { Else }^{c}\end{array}$ & $\begin{array}{l}244 \\
58 \\
4\end{array}$ & $\begin{array}{l}79.7 \% \\
19 \% \\
1.3 \%\end{array}$ \\
\hline 7 & Is fear of loneliness at labor room risk for home delivery? $(n=58)$ & $\begin{array}{l}\text { Yes } \\
\text { No }\end{array}$ & $\begin{array}{l}7 \\
51\end{array}$ & $\begin{array}{l}12.1 \% \\
87.9 \%\end{array}$ \\
\hline 8 & Previous delivery facility type $(\mathbf{n = 2 4 4})$ & $\begin{array}{l}\text { Public hospital } \\
\text { Public health center } \\
\text { Health post }\end{array}$ & $\begin{array}{l}149 \\
91 \\
4\end{array}$ & $\begin{array}{l}61.1 \% \\
37.3 \% \\
1.6 \%\end{array}$ \\
\hline 9 & History of labor companionship $(\mathbf{n}=\mathbf{2 4 4})$ & $\begin{array}{l}\text { Yes } \\
\text { No }\end{array}$ & $\begin{array}{l}100 \\
144\end{array}$ & $\begin{array}{l}41 \% \\
59 \%\end{array}$ \\
\hline
\end{tabular}

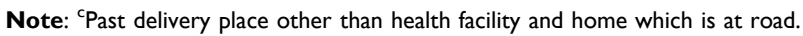
Abbreviation: ANC, antenatal care.

compared to those where staff were not busy during their labor follow-up time (AOR $=0.13,95 \%$ CI: 0.07-0.23).

The odds of utilizing labor companion among women who were followed during their laboring time with only female SBAs was reduced by $63 \%(\mathrm{AOR}=0.37,95 \% \mathrm{CI}$ : 0.17-0.82) compared to those women who were followed by only male SBAs for their laboring time after admission to the health facility (Table 4).

\section{Discussion}

This study aimed to assess utilization of a labor companion and associated factors among women who gave birth at public health institutions of Debremarkos town, Ethiopia. The overall prevalence of labor companion utilization in this study is $14.6 \%$. This study is in line with studies conducted at retrospective record review based in south Brazil (16.7\%), prospective cohort in Reyadis $(14.2 \%),{ }^{35}$ base line evaluation study in south Africa (14.5\%), Nigeria (13.1\%) and Arbaminch, south, Ethiopia (13.8\%). ${ }^{41}$
In contrast to these studies the prevalence of labor companion utilization of this study (14.6\%) is lower than findings from Brazil (42.1\%), ${ }^{33}$ the UAE (59.3\%), Nepal $(19 \%),{ }^{43}$ South Africa $(24.2 \%),{ }^{28}$ Tanzania $(44.7 \%),{ }^{36}$ Kenya (67\%), ${ }^{37}$ Addis Ababa Ethiopia (59.8\%), ${ }^{38}$ and Tigray Ethiopia (39.8\%). ${ }^{39}$ The general possible explanation might be that our study was conducted in the era of COVID-19, which is mainly transmitted via prolonged contact, and the global safety measures of physical distancing and the wearing of personal protective equipment.

The inconsistency of our study from the Brazilian national survey might be due to the difference between the countries' health system policies, which we understand from their demographic health survey. Companionship is a key maternal health indicator in Brazil and is included in the Brazilian national demographic health survey as a key maternal health indicator and the implementation of a labor companion for all women was included in their national law, whereas in our EDHS this service is not included as maternal health service indicator like ANC, 


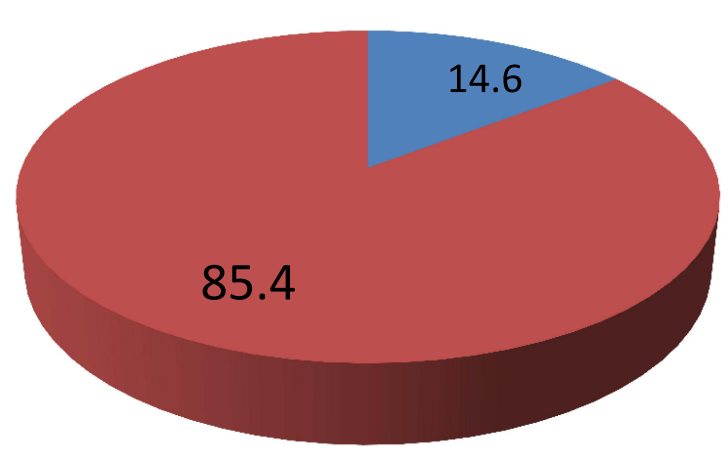

Figure I Magnitude of labor companion utilization among postnatal women at Debremarkos town public health institutions north west, Ethiopia 202I. From the pie-chart I represents the magnitude of utilization and 2 represents the magnitude of non-utilization.

PNC and institutional delivery coverage. In addition to this, the differences between the studies might be due to sociocultural differences and methods, mainly the study setting and data collection tool. In the Brazilian study all postnatal women were included from both private and public health facilities, including baby-friendly hospitals and data were collected using both interview and record review techniques, whereas in this study the sample was collected via interview only at public health institutions.

The possible explanation for lowering of our study compared to a study conducted at $\mathrm{UAE}^{35}$ might be sampling technique, study design, setting, sociocultural difference, socio-economic difference, and study population difference. In our study, women with multiple or singleton delivery, complicated or uncomplicated pregnancies, good or bad birth outcomes and vaginal or cesarean delivery were selected randomly in the first 24 hours post-delivery. However, in their study they select only women with postvaginal uncomplicated deliveries with good birth outcome up to 2 months post-delivery by non random sampling technique.

The possible justification for the inconsistency between studies in Nepal and our study might be the sociodemographic characteristics of the study population, inclusion criterion of population, study setting and measurement tool of outcome variable (labor companion utilization). In this study $99.1 \%$ participants were from a similar ethnic group (Amhara) and women who came for abortion service (gestational age $<28$ weeks) were excluded. Our tool for outcome measurement was not with single yes or no question rather it contains three variables and respondents were from both hospitals and health centers. In Nepal, the study finding was affected mainly with women sociodemographic characteristics. Participants were from different ethnic groups, at hospital level only and they include women who delivered after 22 weeks of gestation and measure utilization with single yes or no question. ${ }^{43}$ The further away from term the more complication as a result being complicated labor (preterm labor) enhance labor companion utilization.

Our study showed that prevalence of labor companion utilization is lower than a study conducted in South Africa. The possibility for the difference might be sampling method, eligibility criterion, and sociodemographic difference. The maximum age group of our study participants was 25 to 34 whereas in Nigeria the maximum participants age category was less than or equal to $25 .^{28}$ Women's age decrease utilization of labor companion increase ${ }^{43}$ our study participants educational status included women with no formal education up to higher education, but they include only women who can read and write. The higher the educational level the higher the likelihood of labor companion utilization. ${ }^{33,37}$ Our study included all postpartum women regardless of birth outcome and mode of delivery with systematic random methods. Whereas their study's sampling technique was convenience, which enhances systematic error and ends up with incorrect generalization, and they exclude women who have suffered loss and women who deliver other than SVD. Labor companion utilization by itself reduces pregnancy loss and the needfor assisted delivery. ${ }^{3,6}$ Prevalence of labor companion utilization may be high among women who deliver by SVD and who have a good birth outcome, compared to their counterparts.

Coverage of labor companion utilization in our study is lower than a study carried out in Tanzania. The possible explanation might be the difference in the study population and sociocultural differences. In our study, the interviewed participants were from hospital, whereas they interview more than $50 \%$ of respondents from a health-center. ${ }^{36}$

Our prevalence study finding is lower than a study conducted in Kenya (67\%). The possible justification might be the study populations, they include participants from private facilities, ${ }^{39}$ whereas in our study the participants are only from public facilities.

Prevalence of labor companion utilization in our study is lower than studies done in Addis Ababa, Ethiopia $(59.8 \%)$ and Tigray, Ethiopia $(39.8 \%){ }^{40}$ The possible explanation for discrepancy from Addis Ababa might be study population. In our study all non-staff postpartum women are included whereas their study participants 
Table 4 Bi-Variable and Multivariable Binary Logistic Regression Analysis of Factors Associated with Labor Companion Utilization, in Debre-Markos Town Public Health Institutions, Northwest Ethiopia, 202I ( $n=548)$

\begin{tabular}{|c|c|c|c|c|}
\hline \multirow[t]{2}{*}{ Variable } & \multicolumn{2}{|c|}{ Labor Companion Utilization } & \multirow[t]{2}{*}{ COR $(95 \% \mathrm{Cl})$} & \multirow[t]{2}{*}{ AOR $(95 \% \mathrm{Cl})$} \\
\hline & Yes & No & & \\
\hline \multicolumn{5}{|l|}{ Age of women } \\
\hline 15 to 24 & 26 & 130 & $2.74(1.143,6.582)^{*}$ & $1.48(0.464,4.717)$ \\
\hline 25 to 34 & 47 & 242 & $2.66(1.163,6.099)^{*}$ & $\mathrm{I} .78(0.654,4.862)$ \\
\hline 35 to 49 & 7 & 96 & 1 & I \\
\hline \multicolumn{5}{|l|}{ Marital status } \\
\hline Married & 76 & 421 & $2.12(0.743,6.059)$ & $1.86(0.585,5.905)$ \\
\hline Separated/single/divorced & 4 & 47 & 1 & 1 \\
\hline \multicolumn{5}{|l|}{ Future desire } \\
\hline Yes & 73 & 349 & $3.56(1.593-7.937)^{* *}$ & $3.63(1.513,8.698)^{* *}$ \\
\hline No & 7 & 119 & I & $\mathrm{I}$ \\
\hline \multicolumn{5}{|l|}{ Gravidity } \\
\hline Primigravida & 46 & 169 & $2.39(1.479,3.875)^{* * *}$ & $0.967(0.289,3.237)$ \\
\hline Multigravida & 34 & 299 & 1 & \\
\hline \multicolumn{5}{|l|}{ Parity } \\
\hline Premipara & 51 & 191 & $2.55(1.560-4.170)^{* * *}$ & $3.49(1.926,6.349)^{* * *}$ \\
\hline Multipara & 29 & 277 & 1 & 1 \\
\hline \multicolumn{5}{|l|}{ Complicated Pregnancy } \\
\hline Yes & 45 & 106 & $4.39(2.685,7.181)^{* * *}$ & $5.53(3.086,9.917)^{* * *}$ \\
\hline No & 35 & 362 & 1 & 1 \\
\hline \multicolumn{5}{|l|}{ Knowledge of respondents } \\
\hline Below mean & 46 & 337 & I & I \\
\hline Mean and above & 34 & 131 & $1.90(1.168,3.095)^{* *}$ & $1.538(0.862,2.744)$ \\
\hline \multicolumn{5}{|l|}{ SBA Busyness } \\
\hline Yes & 34 & 390 & $0.148(0.089,0.245)^{* *}$ & $0.13(0.072,0.228)^{* * *}$ \\
\hline No & 46 & 78 & 1 & 1 \\
\hline \multicolumn{5}{|l|}{ Mode of delivery } \\
\hline SVD & 56 & 342 & I & I \\
\hline $\mathrm{C} / \mathrm{S}$ & 12 & 99 & $0.740(0.382,1.436)$ & $0.844(0.389,1.830)$ \\
\hline Instrumental/episiotomy assisted vaginal delivery & 12 & 27 & $2.714(1.300,5.668)^{*}$ & $1.805(0.759,4.296)$ \\
\hline \multicolumn{5}{|l|}{ Sex of SBAs mostly followed } \\
\hline Both & 21 & 88 & $1.25(0.708,2.195)$ & $0.89(0.458,1.758)$ \\
\hline Female & 10 & 124 & $0.42(0.207,0.860)^{*}$ & $0.37(0.166,0.823)^{* *}$ \\
\hline Male & 49 & 256 & I & 1 \\
\hline
\end{tabular}

Notes: ***P $\leq 0.001$, **P $\leq 0.01$, *P $\leq 0.05$; I; reference category.

Abbreviations: AOR, adjusted odd ratio; $\mathrm{COR}$, crude odd ratio; $\mathrm{Cl}$, confidence interval.

were female health care professionals who had delivery history. Being staff or health care professionals by itself enhances labor companion utilization because of their knowledge and relationship to SBAs. One main reason for non-utilization of a labor companion in the current study and previous studies is the SBAs not allowing this service utilization. $^{41}$ A possible justification for discrepancy from Tigray might be the measurement tool. Our outcome measured three composite variables while they measured with a single question and their outcome of interest is not this service.

There is evidence which supports our study regarding significantly associated factors like complicated pregnancy, future desire, parity, sex of SBAs, and women's 
perceived busyness of SBAs. Among those factors, the statistical association of number of delivery with labor companion utilization is supported by studies done in Brazil, ${ }^{33}$ Kenya, $^{39}$ and Arbaminch, Ethiopia. ${ }^{41}$ In this finding the odds of labor companion utilization for Primipara were 3.5 times higher than Multipara. This finding is consistent with a study done at Arbaminch, Ethiopia (2.05). ${ }^{41}$ This finding was also supported by a study done in Brazil, being Multipara increase a risk of non-utilization of companion with odds by 1.6 times. The possible explanation might be women with no experience of the childbirth process and need more social and support than women who had a history of childbirth. Primigravida women experience fears concerning helplessness, loss of self-control in labor and negative childbirth expectations compared to Multiparas. ${ }^{44}$ Another possible justification might be multiparous women were less worried about pregnancy and less prepared for labor and delivery compared to primiparous women. Multiparous women were expected to have a shorter labor and receive less support from people compared to their counterparts. ${ }^{45}$

Our study concludes that a complicated pregnancy is significantly associated with companionship service utilization during labor. Women who had a complicated pregnancy utilized labor companion 5.5 times more than women who had not had a complicated pregnancy. This finding is supported by a study done at Arbaminch which asserted that the odds of labor companion utilization is 3.5 ( $\mathrm{AOR}=3.48$, CI $95 \%, 1.81,6.70)$ times for women who had complications during labor and delivery compared to theircounterparts. ${ }^{41}$ The possible explanation might be highrisk pregnancies or a complicated labor needs more support from both health professionals and social networks in order to assist in decisionmaking and improve the outcome.

Women's desire for companionship is significantly associated with labor companion utilization. The odds of labor companion utilization among women who had future desire for the service is 3.6 times more likely than those women who had no desire. This finding is supported by a study in Arbaminch. ${ }^{41}$ The possible explanation might be that desire for the service has a strong correlation with culture, education, and knowledge. Most Ethiopian women were delivered at home in the presence of families. From definition to say utilize women should accompanied with their companion of choice. Before deciding desire should be considered.
In this study, unpredictably, women who followed their labor female health care provider reduced prevalence of labor companion utilization by $63 \%$, compared to male, which is difficult to infer because of the stereotype of women working in care and being more emphatic than man. Our finding supported another related study on RMC in Ethiopia. The possible explanation might be that females used violence against patients in their work as a means of creating social distance and maintaining their identity and power in their continued struggle to assert their professional and middle-class identity. ${ }^{46}$ In addition to this female health care providers had triple burdens (reproductive, productive, and community management) which might end up with moral distress and burn out, which may lead to abusive behavior. ${ }^{47}$ Abusive behavior leads to break down of women-centered maternity care, including allowing a companion of choice during childbirth.

According to womens' perspective, skilled birth attendents busyness decrease the likelihood of labor companion utilization by $87.2 \%$, compared to their counterparts. This finding is supported with another related study done in Kenya which showed that the crowdedness of a facility negatively affects choosing to utilize a labor companion. ${ }^{39}$ Facility inputs, like human power, is a determinant factor for labor companion utilization. ${ }^{43}$ When SBAs are busy they can suffer from burn out and behavior change, which may result with nonrespectful maternity care. In addition to this, most of the time the busyness of SBAs is related to the crowdedness of wards which makes it difficult to accommodate laboring mothers and their companion due to privacy issues, space issues, ward cleanliness and bedside chair availability for companion.

\section{Conclusions}

Even though WHO recommend the utilization of labor companions for all women who have a desire, coverage of labor companion utilization in this study was low. This implies that the practice of having a labor companion, which is one main component of RMC, was not practiced during institutional labor and the primdelivery service of study area. Complicated Pregnancy, future desire for the service and being Premipara are predictors which increase the utilization of a labor companion. In contrast to these variables, being followed into labor by female SBAs and SBAs' busyness negatively affect labor companion utilization. Therefore focusing on health care providers, health facilities and women's related factors to 
improve quality of maternity care is undoing the activities of concerned bodies.

\section{Abbreviations}

AOR, Adjusted Odds Ratio; CI, Confidence Interval; COR, Crude Odd Ratio; EDHS, Ethiopian Demographic Health Survey; EMWA, Ethiopian Midwifery Association; LMIC, Low And Middle Income Countries; RMC, Respectful Maternity Care; SBA, Skilled Birth Attendant; SDG, Sustainable Development Goal; UoG, University of Gondar; WHO, World Health Organization.

\section{Data Sharing Statement}

The data set used and analyzed during the current study is available from the corresponding author on the reasonable request.

\section{Ethics Approval and Consent to Participate}

The study proposal was submitted to and approved by School of midwifery ethical review committee under the delegation of UOG institutional review committee. University of Gondar wrote Official letter to Debremarkos town health department and each selected health institutions. An institutional permission was obtained from Debremarkos town health department, Debremarkos referral hospital clinical director. Protective equipment like face mask was given for data collectors and supervisors. Participants were informed clearly about the purpose and benefit of the study and written and signed informed consent was obtained from them with data collectors who wear face mask and keep his/her distant. Those who signed written consent were only participate in the study and leave who were not volunteers to participate and consider as non-response. The confidentiality of responses was maintained throughout the research process by giving code for participant. Personal privacy and cultural norms was respected. All consent form was translated into and administered in Amharic. The author would like to confirm that this study was conducted in accordance with the declaration of Helsinki.

\section{Acknowledgments}

First, I would like acknowledge University of Gondar College of Medicine and Health Sciences for the provision of ethical clearance. Likewise, I am indebted to study participants for their permission and cooperation to participate in this study. In the same way I would like to acknowledge data collectors and supervisors.

\section{Author Contributions}

All authors made a significant contribution to the work reported, whether that is in the conception, study design, execution, acquisition of data, analysis and interpretation, or in all these areas; took part in drafting, revising or critically reviewing the article; gave final approval of the version to be published; have agreed on the journal to which the article has been submitted; and agree to be accountable for all aspects of the work.

\section{Funding}

The funder had no role in the design of the study and collection, analysis and interpretation of data and in writing the manuscript.

\section{Disclosure}

The authors have declared that they have no competing interests in this work.

\section{References}

1. Bowser D, Hill K. Exploring Evidence for Disrespect and Abuse in Facility-Based Childbirth. Boston: USAID-TRAction Project, Harvard School of Public Health; 2010.

2. Hodnett ED, Hofmeyr GJ, Sakala C. Continuous support for women during childbirth. Cochrane Database Syst Rev. 2012;10:4.

3. Bohren MA, Hofmeyr GJ, Sakala C, Fukuzawa RK, Cuthbert A. Continuous support for women during childbirth. Cochrane Database Syst Rev. 2017;(7). doi:10.1002/14651858.CD003766.pub6

4. World Health Organization. WHO Recommendations on Intrapartum Care for a Positive Childbirth Experience. World Health Organization; 2018.

5. Aghor UD. Assessing the effect of companionship during labour on labour and delivery outcomes at mile four hospital, Ishieke Abakaliki, Ebonyi state. Fam Med. 2018.

6. Scott KD, Klaus PH, Klaus MH. The obstetrical and postpartum benefits of continuous support during childbirth. J Wom Health Gend Base Med. 1999;8(10):1257-1264. doi:10.1089/jwh.1.1999.8.1257

7. Wang $\mathrm{M}$, Song $\mathrm{Q}, \mathrm{Xu} \mathrm{J}$, et al. Continuous support during labour in childbirth: a Cross-Sectional Study in a university teaching hospital in Shanghai, China. BMC Pregnancy Childbirth. 2018;18(1):1-7. doi:10.1186/s12884-018-2119-0

8. Campbell DA, Lake MF, Falk M, Backstrand JR. A randomized control trial of continuous support in labor by a lay doula. $J$ Obstet Gynecol Neonatal Nurs. 2006;35(4):456-464. doi:10.1111/j.15526909.2006.00067.x

9. Bruggemann OM, Parpinelli MA, Osis MJ, Cecatti JG, Neto ASC. Support to woman by a companion of her choice during childbirth: a randomized controlled trial. Reprod Health. 2007;4(1):5. doi:10.1186/1742-4755-4-5

10. Banda G, Kafulafula G, Nyirenda E, Taulo F, Kalilani L. Acceptability and experience of supportive companionship during childbirth in Malawi. BJOG. 2010;117(8):937-945. doi:10.1111/ j.1471-0528.2010.02574.x 
11. Omojuwa I. The effect of continuous companionship support on the progress and outcome of labour. Obstet Gynaecol. 2008.

12. Maimbolwa MC. Maternity Care in Zambia: With Special Reference to Social Support. Institutionen för folkhälsovetenskap/Department of Public Health Sciences; 2004.

13. Tekle Bobo Firew KKH, Belachew E, Woldie Mirkuzie FTR. Disrespect and abuse during childbirth in Western Ethiopia: should women continue to tolerate? PLoS One. 2019;14(6):e0217126.

14. Munkhondya BM, Munkhondya TE, Chirwa E, Wang H. Efficacy of companion-integrated childbirth preparation for childbirth fear, self-efficacy, and maternal support in primigravid women in Malawi. BMC Pregnancy Childbirth. 2020;20(1):48. doi:10.1186/ s12884-019-2717-5

15. Balde MD, Nasiri K, Mehrtash H, et al. Labour companionship and women's experiences of mistreatment during childbirth: results from a multi-country community-based survey. BMJ Glob Health. 2020;5 (Suppl 2):e003564. doi:10.1136/bmjgh-2020-003564

16. Chadwick RJ, Cooper D, Harries J. Narratives of distress about birth in South African public maternity settings: a qualitative study. Midwifery. 2014;30(7):862-868. doi:10.1016/j.midw.2013.12.014

17. Bäckström C, Wahn EH. Support during labour: first-time fathers' descriptions of requested and received support during the birth of their child. Midwifery. 2011;27(1):67-73. doi:10.1016/j. midw.2009.07.001

18. Hurissa BFGT, Getinet T. Assessment of provision of women friendly care and associated factors among postnatal mothers at three public hospitals of Jimma Zone, Oromia Region, Ethiopia, 2016. J Biomed Sci. 2017;6(3):26. doi:10.4172/2254-609X.100070

19. Kaba MBT, Tafesse Z, Lingerh W, Ali I, Ali I. Sociocultural determinants of home delivery in Ethiopia: a qualitative study. Int J Womens Health. 2016;8:93-102. doi:10.2147/IJWH.S98722

20. Raven J, Tao F, Kun H, Tolhurst R. The quality of childbirth care in China: women's voices: a Qualitative Study. BMC Pregnancy Childbirth. 2015;15(1):113. doi:10.1186/s12884-015-0545-9

21. White Ribbon Alliance. Respectful Maternity Care. The Universal Rights of Childbearing Women. 2011.

22. Bohren MA, Hunter EC, Munthe-Kaas HM, Souza JP, Vogel JP, Gülmezoglu AM. Facilitators and barriers to facility-based delivery in low-and middle-income countries: a qualitative evidence synthesis. Reprod Health. 2014;11(1):71. doi:10.1186/1742-4755-11-71

23. Asefa A, Bekele D. Status of respectful and non-abusive care during facility-based childbirth in a hospital and health centers in Addis Ababa, Ethiopia. Reprod Health. 2015;12(1):33. doi:10.1186/ s12978-015-0024-9

24. Anastasi E, Borchert M, Campbell OM, et al. Losing women along the path to safe motherhood: why is there such a gap between women's use of antenatal care and skilled birth attendance? A mixed methods study in northern Uganda. BMC Pregnancy Childbirth. 2015;15(1):1-5. doi:10.1186/s12884-015-0695-9

25. World Health Organization. Trends in Maternal Mortality 2000 to 2017: Estimates by WHO, UNICEF. UNFPA, World Bank Group and the United Nations Population Division; 2019.

26. World Health Organization. Maternal Mortality, Fact Sheet No. 348. World Health Organization; 2015.

27. World Health Organization. World health statistics: monitoring health for the SDGs, sustainable development goals; 2019. Available from: https://www.who.int/gho/publications/world_health_statistics/2019/ en/. Accessed Jan 23, 2020.

28. World Health Organization. Standards for Improving Quality of Maternal and Newborn Care in Health Facilities. 2016.

29. Ntombana R, Sindiwe J, Ntombodidi T. Opinions of labouring women about companionship in labour wards. Afr J Midwifery Womens Health. 2014;8(3):123-127. doi:10.12968/ ajmw.2014.8.3.123

30. EMWA. Best Practice in Respectful Maternity Care. Ethiopia midwife association; 2018.
31. FIGO. FIGO guideline mother-baby friendly birthing facilities. Int $J$ Gynaecol Obstet. 2015;128(2):95-99. doi:10.1016/j. ijgo.2014.10.013

32. Montagu D, Sudhinaraset M, Diamond-Smith N, et al. Where women go to deliver: understanding the changing landscape of childbirth in Africa and Asia. Health Policy Plan. 2017;32(8):1146-1152. doi:10.1093/heapol/czx060

33. Diniz CSG, d'Orsi E, Domingues RMSM, et al. Implementation of the presence of companions during hospital admission for childbirth: data from the Birth in Brazil national survey. Cad Saude Publica. 2014;30(suppl 1):S140-S53. doi:10.1590/0102-311X00127013

34. Oliveira FA, Leal GC, Wolff LD, Gonçalves LS. The use of Bologna score to assess normal labor care in maternities. Rev Gaúcha Enferm. 2015;36(spe):177-184.

35. Al-Mandeel HM, Almufleh AS, Al-Damri A-JT. Saudi women's acceptance and attitudes towards companion support during labor: should we implement an antenatal awareness program? Ann Saudi Med. 2013;33(1):28-33. doi:10.5144/0256-4947.2013.28

36. Akin-adenekan OK. Attitude of Nigerian parturients to companionship in labour and assessement of their childbirth experience. Obstet Gynaecol. 2006.

37. Bishanga DR, Massenga J, Mwanamsangu AH, et al. Women's experience of facility-based childbirth care and receipt of an early postnatal check for herself and her newborn in northwestern Tanzania. Int $J$ Environ Res Public Health. 2019;16(3):481. doi:10.3390/ijerph16030481

38. Dynes MM, Binzen S, Twentyman E, et al. Client and provider factors associated with companionship during labor and birth in Kigoma region, Tanzania. Midwifery. 2019;69:92-101. doi:10.1016/ j.midw.2018.11.002

39. Afulani P, Kusi C, Kirumbi L, Walker D. Companionship during facility-based childbirth: results from a mixed-methods study with recently delivered women and providers in Kenya. BMC Pregnancy Childbirth. 2018;18(1):1-28. doi:10.1186/s12884-018-1806-1

40. Fisseha G, Berhane Y, Worku A. Quality of intrapartum and newborn care in Tigray, Northern Ethiopia. BMC Pregnancy Childbirth. 2019;19(1):1-8. doi:10.1186/s12884-019-2184-z

41. Beyene Getahun K, Ukke GG, Alemu BW. Utilization of companionship during delivery and associated factors among women who gave birth at Arba Minch town public health facilities, southern Ethiopia. PLoS One. 2020;15(10):e0240239. doi:10.1371/journal. pone.0240239

42. Diniz CS, d'Orsi E, Domingues RM, et al. Implementation of the presence of companions during hospital admission for childbirth: data from the Birth in Brazil national survey. Cad Saúde Pública. 2014;30:S140-53.

43. Kabakian-Khasholian T, El-Nemer A, Bashour H. Perceptions about labor companionship at public teaching hospitals in three Arab countries. Int $J$ Gynaecol Obstet. 2015;129(3):223-226. doi:10.1016/j.ijgo.2014.12.005

44. Pirdil M, Pirdel L. A comparison of women's expectations of labour and birth with the experiences in primiparas and multiparas with normal vaginal delivery. J Kathmandu Med Coll. 2015;4(1):16-25. doi:10.3126/jkmc.v4i1.15024

45. Norr KL, Block CR, Charles AG, Meyering S. The second time around: parity and birth experience. J Obstet Gynecol Neonatal Nurs. 1980;9(1):30-36.

46. Jewkes R, Abrahams N, Mvo Z. Why do nurses abuse patients? Reflections from South African obstetric services. Soc Sci Med. 1998;47(11):1781-1795. doi:10.1016/S0277-9536(98)00240-8

47. Filby A, McConville F, Portela A. What prevents quality midwifery care? A systematic mapping of barriers in low and middle income countries from the provider perspective. PLoS One. 2016;11(5): e0153391. doi:10.1371/journal.pone.0153391 


\section{Publish your work in this journal}

The International Journal of Women's Health is an international, peerreviewed open-access journal publishing original research, reports, editorials, reviews and commentaries on all aspects of women's healthcare including gynecology, obstetrics, and breast cancer. The

manuscript management system is completely online and includes a very quick and fair peer-review system, which is all easy to use. Visit http://www.dovepress.com/testimonials.php to read real quotes from published authors.

Submit your manuscript here: https://www.dovepress.com/international-journal-of-womens-health-journal 